\title{
H. Royden Jones (1936 - 2013)
}

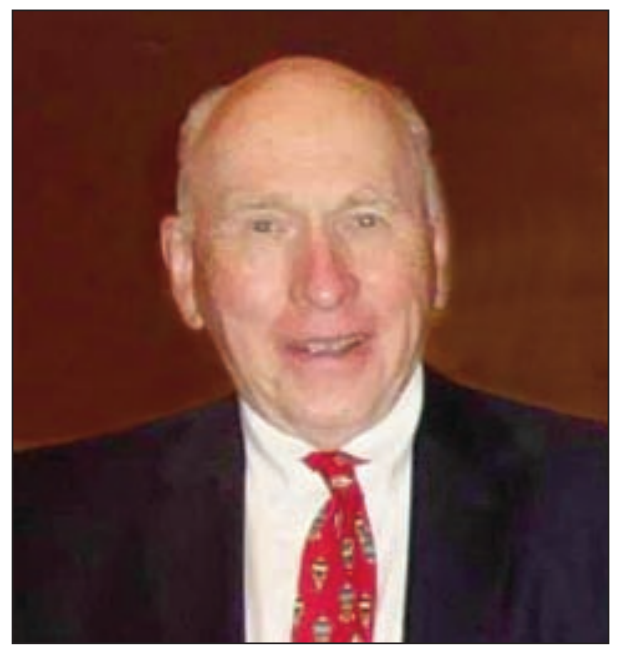

H. Royden Jones, Jr., Clinical Professor of Neurology at Harvard Medical School, Jaime Ortiz Patino Chair of Neurology at the Lahey Medical Center, and Emeritus Director of the electromyography EMG Laboratory at the Children's Hospital in Boston, quietly passed away on June 4, 2013 of self diagnosed cancer of the pancreas. Neurologist, devoted and skilled physician, pioneer in pediatric (EMG), educator, mentor, prolific author, family man, and admired friend and colleague, he leaves behind a remarkable legacy.

H. Royden Jones graduated from Northwestern University's Feinberg School of Medicine. At the Mayo Clinic he completed residencies in internal medicine and neurology and a fellowship in neurological physiology. He ultimately moved to the Boston area with his young family where he remained, and thrived.

More than 30 years ago we dined together in a restaurant lined with pictures of the movie Casablanca. Roy described his initiatives to develop testing of children by EMG techniques. Electromyography is able to localize a disorder to the central nervous system, nerve roots, peripheral nerves, neuromuscular junction or muscle. It is even more important in children, given the uncertainties of the history and neurological examination. William Brown and I invited Roy to write the chapter on pediatric EMG in the second edition of our book, Clinical Electromyography. Roy's own book soon followed, the first on pediatric electromyography, co-written by me and Michael Harper of the Mayo Clinic. Roy was section leader on pediatric electromyography in the two volume book, Neuromuscular Function and Disease, by Brown, Bolton and Aminoff. The field was further informed by two major textbooks edited by Roy and colleagues.

Among H. Royden Jones most relevant and frequently cited articles are the neurological manifestations of bacterial endocarditis, vertebral basilar system infarction, and GuillainBarré syndrome in children. Perhaps his greatest and most enjoyable collaboration had been with Frank Netter, the famed medical illustrator "A picture is worth 1000 words". Roy provided Netter with the text and advice on the illustrations. Michael Aminoff praised Netters beautiful color illustrations, and the lucid text by Roy Jones "One of the outstanding clinical neurologists of his generation".

He took on the arduous task of director of the American Board of Psychiatry and Neurology, at times consulting with his Canadian counterparts. He was a wise counselor to countless students, residents and research fellows.

Finally, Roy was a consummate physician. He would spend hours at night or on the weekend at the bedside of a patient with a difficult neurological problem. He would search the literature and phone his colleagues for advice.

Roy Jones's family was front and center. Mary Norman Jones was a loving and fully supportive wife and mother, despite a busy career in the financial district of Boston. All four children launched successful careers: Roy as a business school professor, Kate Jones Troy as an attorney, Fred as an emergency room physician, and David S. Jones as a university professor, physician and author.

We will miss his quick smile, rugged Welsh features, and engaging conversation. His presence will always be felt as we tackle the many challenging neurological problems.

Charles Bolton

Queen's University

Kingston, Ontario, Canada 